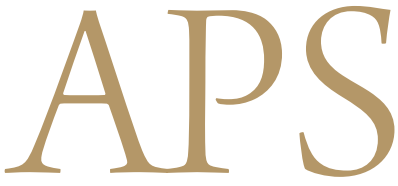

Archives of Plastic Surgery

\title{
Graduate perception of cosmetic surgery training in plastic surgery residency and fellowship programs
}

\author{
Ledibabari Mildred Ngaage ${ }^{1 *}$, Cecelia J Kim ${ }^{2 *}$, Chelsea Harris ${ }^{1}$, Colton HL McNichols ${ }^{3}$, \\ Chinezimuzo Ihenatu ${ }^{2}$, Carly Rosen ${ }^{2}$, Adekunle Elegbede ${ }^{3}$, Selim Gebran ${ }^{4}$, Fan Liang ${ }^{4}$, \\ Erin M Rada ${ }^{2}$, Arthur Nam ${ }^{4}$, Sheri Slezak ${ }^{1}$, Scott D Lifchez ${ }^{3}$, Yvonne M Rasko ${ }^{1}$ \\ ${ }^{1}$ Division of Plastic Surgery, Department of Surgery, University of Maryland Medical Center, Baltimore, MD; ${ }^{2}$ University of Maryland School \\ of Medicine, Baltimore, MD; ${ }^{3}$ Department of Plastic Surgery, John Hopkins University School of Medicine, Baltimore, MD; ${ }^{4}$ Division of \\ Plastic and Reconstructive Surgery, R Adams Cowley Shock Trauma Center, Baltimore, MD, USA
}

Background As the demand for cosmetic surgery continues to rise, plastic surgery programs and the training core curriculum have evolved to reflect these changes. This study aims to evaluate the perceived quality of current cosmetic surgery training in terms of case exposure and educational methods.

Methods A 16-question survey was sent to graduates who completed their training at a U.S. plastic surgery training program in 2017. The survey assessed graduates' exposure to cosmetic surgery, teaching modalities employed and their overall perceived competence. Case complexity was characterized by the minimum number of cases needed by the graduate to feel confident in performing the procedure.

Results There was a 25\% response rate. The majority of respondents were residents (83\%, $n=92)$ and the remaining were fellows $(17 \%, n=18)$. Almost three quarters of respondents were satisfied with their cosmetic training. Respondents rated virtual training as the most effective learning modality and observing attendings' patients/cases as least effective. Perceived competence was more closely aligned with core curriculum status than case complexity, i.e. graduates feel more prepared for core cosmetic procedures despite being more technically difficult than non-core procedures.

Conclusions Despite the variability in cosmetic exposure during training, most plastic surgery graduates are satisfied with their aesthetic training. Incorporation of teaching modalities, such as virtual training, can increase case exposure and allow trainees more autonomy. The recommended core curriculum is adequately training plastic surgery graduates for common procedures and more specialized procedures should be consigned to aesthetic fellowship training.

Keywords Aesthetic surgery / Residency / Fellowship / Curriculum / Training
Correspondence:

Ledibabari Mildred Ngaage Division of Plastic Surgery, Department of Surgery, University of Maryland Medical Center, $22 \mathrm{~S}$ Greene St, Baltimore, MD 21230, USA Tel: +1-410-328-2360

Fax: +1-410-328-0638

E-mail: Imngaage@som.umaryland.edu

*The two authors contributed equally to this work.

Received: March 10, $2019 \bullet$ Revised: November 13, $2019 \bullet$ Accepted: November 23, 2019

pISSN: 2234-6163 • elSSN: 2234-6171 • https://doi.org/10.5999/aps.2019.00409 • Arch Plast Surg 2020;47:70-77

Copyright $($ C 2020 The Korean Society of Plastic and Reconstructive Surgeons

This is an Open Access article distributed under the terms of the Creative Commons Attribution Non-Commercial License (https://creativecommons.org/

licenses/by-nc/4.0/) which permits unrestricted non-commercial use, distribution, and reproduction in any medium, provided the original work is properly cited. 


\section{INTRODUCTION}

The demand for cosmetic plastic surgery is continuing to rise. Over the past 5 years, there has been an increase in cosmetic surgical and non-surgical procedures by $27 \%$ and $38 \%$, respectively [1]. As the demand for all types of cosmetic procedures continues to grow, training for plastic surgeons is increasingly important. However, a 2011 study by Oni et al. [2] indicates that only half of graduating plastic surgery residents feel comfortable integrating aesthetic surgery into their practice. Thus, it is essential to re-evaluate the plastic surgery curriculum to reflect changes in the current field.

Despite general acknowledgement that a gap exists between skills necessary to be a competent aesthetic surgeon and existing curriculum [3], little is understood about which specific elements of training are most lacking. Significant variability exists in cosmetic education across plastic surgery training programs globally [4-8] and it can also be difficult to generate adequate case volume for trainees owing to the growing number of cosmetic procedures performed in private surgery centers $[4,5]$. This can lead to deficiencies in knowledge [4]. Furthermore, studies demonstrate that program directors often disagree with residents regarding the quality of cosmetic surgery training and the best approach to provide exposure $[2,9,10]$. Historically, these differences have translated into wide variability in trainees' confidence performing core aesthetic procedures. The Accreditation Council for Graduate Medical Education (ACGME) sets the minimum case numbers for "core procedures" which is one of the essential metrics to assess resident experience and competence [11]. In 2014, ACGME increased the minimum aesthetic case number from 55 to 150 to augment and standardize cosmetic training. These recent changes also increased resident exposure to facial aesthetic and body contouring procedures as well as botulinum toxin injection and fillers [12]. Yet whether this has changed residents' perception of their training has not been defined.

To better evaluate the impact of these changes and assess residents' perception of their cosmetic surgery training, we performed a survey of recent plastic surgery graduates. We aimed to assess three main areas of cosmetic surgery training: the proportion of training dedicated to aesthetic surgery, the effectiveness of educational modalities, and their overall perceived competence.

\section{METHODS}

\section{Study participants}

The study was reviewed and confirmed to be exempt by the
University of Maryland Institutional Review Board (HP00088644). We identified recent plastic surgery graduates who had completed either residency or fellowship training through the list of candidates eligible for the 2017 oral examination in the United States as listed on American Board of Plastic Surgery Annual Newsletter [13]. An electronic 16-question survey was then sent to the eligible plastic surgeons. Participants were grouped into those who had completed a plastic surgery residency only ("residents"), and those who has also completed a cosmetic fellowship ("fellows"). Responses were collected from June 2017 to March 2018.

\section{Survey design}

The survey was developed using SurveyMonkey (Palo Alto, CA, USA). The survey consisted of 16 questions which consisted of three number of Likert-like scale questions, eleven multiple choice questions and two free text style questions. The full survey can be viewed online in Supplemental Material 1. The survey provided the option to skip questions. Two respondents were excluded due to incomplete surveys. Incentives were not provided to any of the participants.

\section{Survey content}

Cosmetic exposure was assessed through multiple choice questions. Different teaching modalities were evaluated on a Likertlike scale with two verbal anchors (1, worst teaching modality; 7, best way to learn). Participants were also asked to rate their satisfaction with their cosmetic surgery training on a Likert scale with five verbal anchors ( 1 , not at all satisfied; 2 , somewhat satisfied; 3 , satisfied; 4, mostly satisfied; 5 , very satisfied). Free text response was used to allow respondents to give feedback on methods to improve cosmetic surgery training.

Perceived surgical competence was assessed through multiple choice questions. Participants were asked to identify procedures (from a specified list) that they did not feel adequately prepared to perform after graduation. There was no limit to the number of procedures that could be chosen by the respondent. We created a list of cosmetic surgeries selected from ACGME core procedures list [12] and augmented with emerging cosmetic procedures not part of the ACGME core $[14,15]$. To assess case complexity, we asked graduates to estimate the minimum number of cases they would need to complete for each particular procedure before they could feel confident in performing the procedure independently. This was also evaluated through multiple choice questions. If the majority of respondents reported that $<10$ cases would be needed before feeling confident in performing the procedure, then the procedure was perceived to be "technically simple." Conversely, if the majority of respon- 
dents reported that $>20$ cases would be needed before feeling confident in performing the procedure, then the procedure was perceived to be "technically difficult."

\section{Data analysis}

Data was analyzed using JMP 11.0 (SAS Institute, Cary, NC, USA). The differences in categorical variables were analyzed using Pearson's chi-square. The differences in ordinal variables used by the Likert-like scales were analyzed using the MannWhitney U-test and Kruskal-Wallis test, as appropriate. P-values $<0.05$ were considered statistically significant.

\section{RESULTS}

\section{Participants}

Based on the potential oral examination candidates, 443 residents and fellows were contacted. A total of 110 respondents completed the survey, achieving a $25 \%$ survey response rate. Respondent demographic data is summarized in Table 1 and were similar to the overall resident population $[2,10]$. Ninetytwo respondents (84\%) were residents and $18(16 \%)$ were cosmetic fellows, and the majority of respondents were male. We grouped the regional distribution of respondents into eight regions. Most of the respondents completed their training from the West, Mid-Atlantic, and Southwest and six graduates completed their training outside of the United States. The median time from graduation among respondents was 2 years.

\section{Cosmetic exposure}

Most residents reported that their current practice featured

Table 1. Cosmetic surgery training survey responses from graduate residents and fellows in plastic surgery programs

\begin{tabular}{|lcc|}
\hline Variable & Resident $(\mathbf{n}=\mathbf{9 2})$ & Fellow $(\mathbf{n}=\mathbf{1 8})$ \\
\hline Sex & $64(70)$ & $14(74)$ \\
Male & $28(30)$ & $4(21)$ \\
Female & & \\
Regions of the US & $23(25)$ & $4(21)$ \\
West & $18(20)$ & $2(11)$ \\
Mid-Atlantic & $15(16)$ & $4(21)$ \\
Southwest & $10(11)$ & $3(16)$ \\
South Atlantic & $13(14)$ & 0 \\
Northeast central & $8(9)$ & $2(11)$ \\
Northeast & 0 & $1(5)$ \\
Northwest central & $3(3)$ & 0 \\
Southeast & $2(2)$ & $2(11)$ \\
Canada & $63(73)$ & $16(84)$ \\
Cosmetic clinica) & \\
\hline Values are presented as number (\%). & \\
a)Cosmetic clinic dedicated cosmetic clinic during training. & \\
\hline
\end{tabular}

$<10 \%$ of cosmetic surgery compared to the fellows who reported $51 \%-75 \%$ as the most common proportion of their current practice dedicated to cosmetic surgery (Table 2). Both residents (76\%) and cosmetic fellows (100\%) planned to increase the proportion of cosmetic surgery performed in their practice within the next 5 years.

The amount of time dedicated to cosmetic surgery training during residency and fellowship years varied for graduates with an overall median duration of 4-6 months. Half of the residents (52\%) reported a duration of 4-6 months whereas half of the fellows (50\%) reported a duration of $>9$ months (Table 3). Of the residents, $53 \%$ reported that cosmetic surgery training was a factor in their decision for ranking their plastic surgery residency programs. As a follow up question, they were asked to rate their satisfaction with their cosmetic surgery training. The majority of residents and fellows (71\%) reported being at least satisfied with their cosmetic training (Table 4). Residents who did not pursue a cosmetic fellowship were asked how their decision affected their cosmetic practice. A minority of respondents responded

Table 2. Percentage of practice composed of solely cosmetic surgery in plastic surgery graduates

\begin{tabular}{|lcc|}
\hline $\begin{array}{l}\text { Proportion of clinical practice } \\
\text { composed of cosmetic surgery }\end{array}$ & $\begin{array}{c}\text { Resident } \\
(\mathbf{n}=\mathbf{9 2})\end{array}$ & $\begin{array}{c}\text { Fellow } \\
(\mathbf{n}=\mathbf{1 8})\end{array}$ \\
\hline$<10$ & $41(45)$ & 0 \\
$10-25$ & $28(30)$ & $1(6)$ \\
$26-50$ & $14(15)$ & $5(28)$ \\
$51-75$ & $6(7)$ & $7(39)$ \\
$>75$ & $3(3)$ & $5(28)$ \\
\hline Values are presented as number (\%). & &
\end{tabular}

Table 3. Amount of time dedicated to cosmetic surgery training during residency and fellowship

\begin{tabular}{|lcc|}
\hline $\begin{array}{c}\text { Dedicated cosmetic surgery } \\
\text { training }\end{array}$ & $\begin{array}{c}\text { Resident } \\
(\mathbf{n}=\mathbf{9 2})\end{array}$ & $\begin{array}{c}\text { Fellow } \\
(\mathbf{n}=18)\end{array}$ \\
\hline$<1$ mon & $2(2)$ & 0 \\
$1-3$ mon & $25(29)$ & $1(6)$ \\
$4-6$ mon & $45(52)$ & $2(11)$ \\
$7-9$ mon & $10(12)$ & $6(33)$ \\
$>9$ mon & $5(6)$ & $9(50)$ \\
\hline Values are presented as number (\%). & & \\
\hline
\end{tabular}

Table 4. Graduates' satisfaction with their cosmetic surgery training during residency and aesthetic fellowship

\begin{tabular}{|lccccc|}
\hline \multicolumn{7}{|c|}{ Not at all } & Somewhat & Satisfied & Mostly & Very \\
\hline Residency & $3(3)$ & $20(23)$ & $24(28)$ & $32(37)$ & $8(9)$ \\
Fellowship & 0 & $3(17)$ & $3(17)$ & $8(44)$ & $4(22)$ \\
\hline
\end{tabular}


that they regret not attaining a fellowship $(22 \%)$ and do not plan on performing much cosmetic surgery (24\%). Many $(n=40$, 44\%) felt that they did not need a fellowship to be comfortable with cosmetic surgery. Of the graduates who pursued cosmetic fellowship training, $89 \%$ rated their fellowship as very useful whereas $11 \%$ rated their fellowship as somewhat useful.

\section{Educational modalities}

Respondents rated educational modalities on a 7-point Likert scale. Of the listed teaching platforms, graduates preferred virtual learning and rated observing attendings' cases as the least preferred teaching modality. Although, there was no significant difference in preference when all teaching modalities were compared $(\mathrm{P}=0.45)$ (Table 5) or when most or least preferred were compared ( 6 vs. $2.5, \mathrm{P}=0.20)$. All graduates were asked how to provide short answers on how to improve cosmetic training which were then grouped into key themes. The most common recommendation by graduates to improve training was to increase the number of cosmetic cases and training (Fig. 1).

\section{Table 5. Median ratings of preferred teaching modalities} reported by plastic surgery graduates on a 7-point Likert scale ${ }^{a)}$

\begin{tabular}{|llc|}
\hline Rank & Teaching modalities & Median score (IOR) \\
\hline 1 & Virtual learning & $6(2-7)$ \\
2 & Cadaver dissection & $5(4-6)$ \\
3 & Webinars & $4(2-5)$ \\
3 & Books, journals & $4(4-5)$ \\
4 & Conferences, lectures & $3(2-5)$ \\
4 & Resident cosmetic clinic & $3(2-7)$ \\
5 & Attendings' patients/cases & $2.5(1-6)$ \\
\hline IQR, interquartile range. & \\
alIn 7-point Likert scale, 1 denotes worst teaching modality and 7 denotes best \\
teaching modality as preferred by plastic surgery graduates. \\
\hline
\end{tabular}

\section{Perceived competence and case complexity}

Graduate residents (Table 6) and fellows (Table 7) evaluated how prepared they felt to perform an aesthetic procedure at the point of graduation from residency and cosmetic fellowship, respectively. The five aesthetic procedures graduates felt the most prepared were the same for all respondents: upper blepharoplasty, breast reduction, abdominoplasty, brachioplasty, and liposuction. Both residents and fellows felt inadequately prepared to perform endoscopic breast augmentation, endoscopic browlift, hair transplantation, and other noninvasive therapies.

\section{Table 6. Number of graduated plastic surgery residents}

that felt inadequately prepared to perform each cosmetic procedure (ranked from least to most prepared)

\begin{tabular}{|clc|}
\hline Rank & Cosmetic procedures & Residents $(\mathbf{n}=\mathbf{9 2})$ \\
\hline 1 & Endoscopic breast augmentation & 73 \\
2 & Buttock augmentation & 64 \\
3 & Endoscopic browlift & 55 \\
4 & Hair transplantation & 54 \\
4 & Other noninvasive therapy & 54 \\
5 & Rhinoplasty & 50 \\
5 & Facelift & 50 \\
6 & Laser therapy & 36 \\
7 & Lower body lift & 30 \\
8 & Thigh lift & 21 \\
9 & Lower blepharoplasty & 13 \\
10 & Open browlift & 12 \\
11 & Lateral canthopexy/plasty & 11 \\
12 & Chin implant/face implant & 9 \\
13 & Botox and fillers & 8 \\
14 & Open breast augmentation & 7 \\
15 & Mastopexy & 3 \\
15 & Upper blepharoplasty & 3 \\
16 & Breast reduction & 2 \\
16 & Abdominoplasty & 2 \\
16 & Brachioplasty & 2 \\
16 & Liposuction & 2 \\
\hline
\end{tabular}

Fig. 1. Graduates' recommendations for improved cosmetic training

Plastic surgery graduates' (residents and aesthetic fellows) feedback to improve cosmetic surgery training.

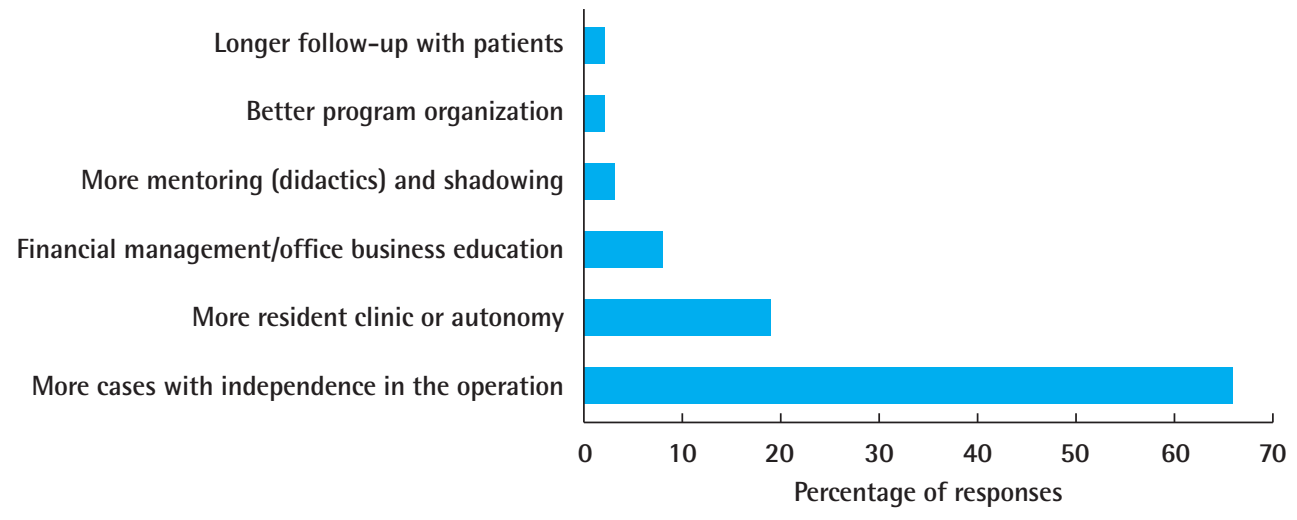


Table 7. Number of graduated aesthetic fellows that felt inadequately prepared to perform each cosmetic procedure (ranked from least to most prepared)

\begin{tabular}{|clc|}
\hline Rank & \multicolumn{1}{c}{ Cosmetic procedure } & Fellow $(\mathbf{n}=\mathbf{1 8})$ \\
\hline 1 & Endoscopic breast augmentation & 14 \\
2 & Other noninvasive therapy & 12 \\
3 & Endoscopic browlift & 11 \\
4 & Hair transplantation & 10 \\
4 & Laser therapy & 10 \\
5 & Rhinoplasty & 9 \\
6 & Buttock augmentation & 7 \\
6 & Facelift & 7 \\
7 & Chin implant/face implant & 4 \\
8 & Lower body lift & 3 \\
9 & Lower blepharoplasty & 2 \\
9 & Open browlift & 2 \\
9 & Thigh lift & 2 \\
9 & Botox and fillers & 2 \\
9 & Mastopexy & 2 \\
10 & Lateral canthopexy/plasty & 1 \\
10 & Open breast augmentation & 1 \\
11 & Upper blepharoplasty & 0 \\
11 & Breast reduction & 0 \\
11 & Abdominoplasty & 0 \\
11 & Brachioplasty & 0 \\
11 & Liposuction & 0 \\
\hline
\end{tabular}

There was crossover between the procedures that graduates felt inadequately prepared to perform and procedures not listed as part of the ACGME core (Table 8). Case complexity was not related to perceived competence. This analysis was repeated after separating responses from residents and fellows. The technical difficulty of procedures did not differ from overall graduate opinion when responses were analyzed from residents alone. However, the number of fellows was too low to make any other significant conclusions.

\section{DISCUSSION}

This survey represents the most recent report on the perception of cosmetic training by plastic surgery graduates. Our results revealed three important findings: (1) despite variable cosmetic exposure amongst graduates there is overall satisfaction with cosmetic training; (2) the best perceived educational modality for graduates was virtual training; and (3) ACGME core curriculum is a greater determinant of graduate preparedness than case complexity.

More than half of the residents reported that cosmetic surgery

Table 8. Number of graduates (residents and aesthetic fellows) and the number of cases needed to feel confident in performing each procedure

\begin{tabular}{|c|c|c|c|c|c|}
\hline \multirow{2}{*}{ Procedure } & \multicolumn{3}{|c|}{ Case } & \multirow{2}{*}{ P-value } & \multirow{2}{*}{$\begin{array}{c}\text { No. of cases recommended } \\
\text { by } \text { ACGME) }^{\text {a) }}\end{array}$} \\
\hline & $0-10$ & $11-20$ & $>20$ & & \\
\hline Chin implant/face implantb) & $63(60)$ & $28(27)$ & $15(14)$ & $<0.001^{d)}$ & $\mathrm{NL}$ \\
\hline Hair transplantation ${ }^{\text {b) }}$ & $62(59)$ & $29(28)$ & $14(13)$ & $<0.001^{d)}$ & $\mathrm{NL}$ \\
\hline Open browlifft) & $61(58)$ & $30(29)$ & $14(13)$ & $<0.001^{d)}$ & $\mathrm{NL}$ \\
\hline Buttock augmentation ${ }^{\text {b) }}$ & $57(54)$ & $33(31)$ & $15(14)$ & $<0.001^{d)}$ & $\mathrm{NL}$ \\
\hline Endoscopic breast augmentation ${ }^{\text {b) }}$ & $57(54)$ & $34(32)$ & $14(13)$ & $<0.001^{d)}$ & $\mathrm{NL}$ \\
\hline Endoscopic browlift & $57(54)$ & $35(33)$ & $13(12)$ & $<0.001^{d)}$ & $\mathrm{NL}$ \\
\hline Upper blepharoplasty ${ }^{\mathrm{b}}$ & $56(53)$ & $32(31)$ & $17(16)$ & $<0.001^{d)}$ & 20 \\
\hline Thigh lift & $55(52)$ & $33(31)$ & $15(14)$ & $<0.001^{d)}$ & 2 \\
\hline Lower body lift ${ }^{b)}$ & $53(51)$ & $37(35)$ & $15(14)$ & $<0.001^{d)}$ & 2 \\
\hline Brachioplasty ${ }^{b)}$ & $51(49)$ & $39(37)$ & $15(14)$ & $<0.001^{d)}$ & 2 \\
\hline Other noninvasive therapy ${ }^{b)}$ & $51(49)$ & $25(24)$ & $29(28)$ & $0.004^{d)}$ & $\mathrm{NL}$ \\
\hline Lower blepharoplasty & $49(47)$ & $37(35)$ & $19(18)$ & $0.002^{d)}$ & 20 \\
\hline Lateral canthopexy/plasty & $48(46)$ & $41(39)$ & $16(15)$ & $<0.001^{d)}$ & $\mathrm{NL}$ \\
\hline Laser therapy & $46(44)$ & $28(27)$ & $31(30)$ & 0.070 & 10 \\
\hline Liposuction & $44(42)$ & $38(36)$ & $23(22)$ & 0.035 & 15 \\
\hline Open breast augmentation & $40(38)$ & $38(36)$ & $27(26)$ & 0.247 & 16 \\
\hline Abdominoplasty & $38(36)$ & $43(41)$ & $24(23)$ & 0.063 & 10 \\
\hline Breast reduction & $35(33)$ & $42(40)$ & $28(27)$ & 0.247 & 24 \\
\hline Mastopexy & 35 (33) & $41(39)$ & $29(28)$ & 0.357 & 12 \\
\hline Botox and fillers & $33(31)$ & $34(32)$ & $38(36)$ & 0.819 & 7 \\
\hline Facelift & $32(31)$ & $39(37)$ & $34(32)$ & 0.691 & 10 \\
\hline Rhinoplastyc) & $18(17)$ & $37(35)$ & $50(48)$ & $<0.001^{d)}$ & 10 \\
\hline \multicolumn{6}{|c|}{$\begin{array}{l}\text { Values are presented as number (\%). } \\
\text { ACGME, Accreditation Council for Graduate Medical Education; NL, not listed. } \\
\text { a)The recommended number of cases for each procedure as advised by ACGME; ')Technically simple procedures; 'Technically difficult procedures; ')Statistically significant, } \\
\mathrm{P}<0.05 \text {. }\end{array}$} \\
\hline
\end{tabular}


training was a factor in their decision for ranking plastic surgery residency programs. This emphasizes the importance of providing high-quality exposure and training in aesthetic surgery. We report a similar duration of training spent on cosmetic surgery as found in the earlier 2017 survey (4-6 months vs. 3-6 months) [9]. Nonetheless, some variability in cosmetic exposure was noted between respondents. This variability may be explained by the preferences of residency programs and/or program directors whereby different programs may place greater emphasis on reconstructive plastic surgery than aesthetic training $[7,10]$. Additionally, it is possible that graduates guide their own surgical exposure to some degree and those pursuing other sub-specialties pursue do not seek out as much cosmetic exposure as others who are pursuing an aesthetic-based practice. This is supported by our findings which demonstrate that most of the respondents were satisfied with the current level of cosmetic exposure despite gaps in knowledge. This concept highlights a potential novel approach to plastic surgery training. The adoption of a flexible training approach may allow trainees more autonomy in choosing the procedures they are exposed to and increase resident satisfaction. The emerging use of a flexible training track in general surgery has resulted in greater satisfaction and enabled trainees to "track" to their area of subspecialty interest sooner than traditional fellowship training allows [16]. Through tracking, plastic surgery programs may allow interested residents to advance their skills without compromising satisfaction of residents who have less interest in cosmetic exposure.

The majority of graduates felt that cosmetic training could be improved by increasing the number of cases and independence. However, due to time constraints in training and number of cosmetic procedures performed in private surgery centers this may not be possible $[4,5]$. Nonetheless, modifying teaching modality may offer another avenue for improved graduate training experience. Our survey results show residents perceived virtual learning to be the best educational modality. Virtual training in plastic surgery helps surgeons visualize and plan procedures by selecting incision sites, suturing, and viewing predicted outcomes [17]. This is particularly important since visualization is paramount in acquiring spatially-complex surgical skills. Additionally, virtual training allows the trainee to complete the task in their own time without time pressures or judgement. This offers an interesting approach to increase graduate cosmetic surgery exposure without the need for increased case numbers. Modifying educational activities to include video libraries and web modules can further provide accessible tools for trainee surgeons to learn clinical and surgical skills $[18,19]$. Surprisingly, the lowest ranked modalities were observing attendings' patients/cases and residents' cosmetic clinics which differs from previous studies $[2,5,11]$. This may be explained by the level of independence associated with these teaching methods. Autonomy marks the transition from training to clinical practice and has been shown to increase surgical independence and perceived competence [20]. The extent of autonomy given to residents when involved in attendings' cases or residents' clinics has been shown to be considerably less than initially thought [21]. Barriers to resident autonomy are the need to increase case efficiency, concern surrounding patient outcomes, and patient and institutional expectations of attending surgeon involvement [21].

Despite the greater proportion of training dedicated to cosmetic surgery during fellowship, both residents and fellows had shared a similar deficiency in specific procedures. This suggests that a consistent gap exists in cosmetic plastic surgery training. Interestingly, perceived case complexity (needing $<10$ procedures to feel confident performing) did not necessarily mean that graduates felt prepared to complete these cases at the end of training. For example, although endoscopic browlift and hair transplantation were rated as technically simpler than rhinoplasty, fewer graduates felt prepared to perform them. Rather, perceived competence was more closely aligned with the curriculum status of the procedure. Our results show that graduates felt most prepared for procedures included in the ACGME core curriculum and inadequately prepared for non-ACGME core procedures which suggests that the recent changes by ACGME are effective in providing adequate preparation for the recommended core procedures. The role of ACGME is to identify the key procedures that a graduate must be competent in performing. Emerging cosmetic surgeries, such as buttock augmentation, are gaining popularity but still represent a small cohort of patients [22] which may explain their absence on the list of ACGME core procedures. Thus, these niche procedures may be consigned to aesthetic fellowship without decreasing satisfaction. This may be particularly appropriate given the reported disparity in the proportion of cosmetic surgery in current practice between residents and aesthetic fellows.

Additionally, our study shows that a majority of graduates felt inadequately prepared for endoscopic procedures. There has been a growing trend in adopting minimally invasive surgeries (MIS) in aesthetic surgery due to better scar cosmesis and plastic surgeon opinion is that the future of plastic surgery will include endoscopic procedures [15]. However, MIS training can be difficult to incorporate into the resident curriculum as it creates a challenging environment for educators who must provide experience in two unique skills sets for the same operations $[23,24]$. This once again emphasizes the importance of extending the teaching curriculum beyond the "one-size-fits-all" model 
to allow graduates the opportunity to practice cosmetic procedures outside the ACGME recommended core curriculum. A flexible training approach may mean that this training could be provided to the interested few instead of the entire cohort. Thus, minimizing costs, increasing feasibility and not endangering satisfaction.

Our study highlights potential gaps in current cosmetic training amongst plastic surgery graduates and underscores the importance of use of multimodal and innovative teaching modalities to prepare residents to perform aesthetic procedures. However, there are limitations. It is important to acknowledge our low response rate $(25 \%)$ that could impact the generalizability of our results. Due to its cross-sectional nature, this study is not able to establish a causal relationship between ACGME minimum requirements and graduate confidence in performing cosmetic procedures. Graduates' opinions on different teaching modalities were evaluated using Likert-like scales. Although a Likert-type scale is a quantifiable and universal method for survey collection, it can be subjected to distortion as each respondent will have a different reference point [25]. Additionally, we did not use a positive or negative control to calibrate graduate responses. Furthermore, use of an absolute number of cases is not a perfect metric to assess surgical competence as individual ability dictates the number of cases needed to achieve competence i.e. one graduate may need three cases to achieve competence whereas another may need 15 cases of the same procedure. The use of multiple choice questions which gives pre-determined answers, and the presence of recall bias are also possible limitations inherent to the study as well. Finally, we used a 16-question survey to allow for simplicity and a higher completion rate. Another limitation was the use of a non-validated study. Currently, there are no validated questionnaires to evaluate plastic surgery graduate experience of training but this study may be the first step in creating a validated survey for that purpose.

Recent changes to the ACGME minimum requirements reflect the importance of aesthetic surgery training and increased exposure for trainees. Our results show that overall graduates are satisfied with their current cosmetic exposure during training but improvements can be made by early exposure or increased access to cases. In order to meet the demands of a changing plastic surgery landscape, accrediting agencies and residency programs should consider adopting dynamic training pathways and novel modalities, such as virtual training, that will allow interested residents to increase their cosmetic surgery skills. The ACGME core curriculum status of a cosmetic procedure is a greater determinant of graduate perceived competence than case complexity, i.e. graduates feel more prepared for ACGME core cosmetic procedures despite being more technically difficult than non-ACGME procedures. The recommended core curriculum is adequately training plastic surgery graduates for common procedures and the more specialized procedures should be consigned to aesthetic fellowships.

\section{NOTES}

\section{Conflict of interest}

No potential conflict of interest relevant to this article was reported.

\section{Ethical approval}

The study was reviewed and confirmed to be exempt by the University of Maryland Institutional Review Board (HP-000 88644).

\section{Author contribution}

Study conception: all authors. Study design: Ngaage LM, McNichols CH, Ihenatu C, Elegbede A, Liang F, Rada EM, Nam A, Slezak S, Lifchez SD, Rasko YM. Data analysis: Ngaage LM, Kim CJ, Harris C, Rasko YM. Data collection: Kim CJ, Ihenatu C. Data acquisition: McNicholls CH, Rosen C, Gebran S, Liang F, Rada EM, Nam A, Rasko YM. Manuscript editing: Ngaage LM, Harris C, McNichols CH, Elegbede A, Liang F, Rada EM, Nam A, Slezak S, Lifchez SD, Rasko YM. Initial manuscript draft: Ngaage LM, Kim CJ. Revisions and responding to reviewers: Ngaage LM. Final approval of manuscript: all authors.

\section{ORCID}

Ledibabari M Ngaage https://orcid.org/0000-0001-5802779X

Adekunle Elegbede https://orcid.org/0000-0002-1577-504X

Selim Gebran https://orcid.org/0000-0001-8481-4201

Erin M Rada https://orcid.org/0000-0003-0320-1919

Yvonne MRasko https://orcid.org/0000-0003-0051-0273

\section{Supplementary material}

Supplemental Material 1. Study survey.

Supplemental data can be found at: https://doi.org/10.5999/ aps.2019.00409.S001.

\section{REFERENCES}

1. American Society for Aesthetic Plastic Surgery (ASAPS). Cosmetic Surgery National Data Bank Statistics [Internet]. Garden Grove, CA: ASAPS; c2017 [cited 2019 Feb 2]. Available from: https://www.surgery.org/sites/default/ files/ASAPS-Stats2017.pdf. 
2. Oni G, Ahmad J, Zins JE, et al. Cosmetic surgery training in plastic surgery residency programs in the United States: how have we progressed in the last three years? Aesthet Surg J 2011;31:445-55.

3. Momeni A, Kim RY, Wan DC, et al. Aesthetic surgery training during residency in the United States: a comparison of the integrated, combined, and independent training models. Plast Surg Int 2014;2014:281923.

4. Momeni A, Goerke SM, Bannasch H, et al. The quality of aesthetic surgery training in plastic surgery residency: a survey among residents in Germany. Ann Plast Surg 2013;70: 704-8.

5. Chivers QJ, Ahmad J, Lista F, et al. Cosmetic surgery training in Canadian plastic surgery residencies: are we training competent surgeons? Aesthet Surg J 2013;33:160-5.

6. Morrison CM, Rotemberg SC, Moreira-Gonzalez A, et al. A survey of cosmetic surgery training in plastic surgery programs in the United States. Plast Reconstr Surg 2008;122: 1570-8.

7. Zheng J, Zhang B, Yin Y, et al. Comparison of plastic surgery residency training in United States and China. Ann Plast Surg 2015;75:672-8.

8. Smith J, Kilshaw A, Williams A. UKTEAS: United Kingdom training experience in aesthetic surgery. J Plast Reconstr Aesthet Surg 2016;69:1008-9.

9. McNichols CHL, Diaconu S, Alfadil S, et al. Cosmetic surgery training in plastic surgery residency programs. Plast Reconstr Surg Glob Open 2017;5:e1491.

10. Hashem AM, Waltzman JT, D'Souza GF, et al. Resident and program director perceptions of aesthetic training in plastic surgery residency: an update. Aesthet Surg J 2017;37:83746.

11. Kraft CT, Harake MS, Janis JE. Longitudinal assessment of aesthetic plastic surgery training in the United States: the effect of increased ACGME case log minimum requirements. Aesthet Surg J 2019;39:NP76-82.

12. Accreditation Council for Graduate Medical Education (AGGME). Operative minimums effective July 1, 2014 review committee for plastic surgery [Internet]. Chicago, IL: AGGME; c2017 [cited 2019 Feb 2]. Available from: https:// www.acgme.org/Portals/0/PFAssets/ProgramResources/ Operative_Minimums_effective_07012014.pdf.

13. Karch MA. Potential oral exam candidates [Internet]. The American Board of Plastic Surgery. Philadelphia, PA; c2017 [cited 2018 Oct 30]. Available from: https://www.abplasticsurgery.org/media/11090/2017-abps-annual-newsletter.pdf.
14. American Society of Plastic Surgeons (ASPS). 2016 Cosmetic plastic surgery statistics cosmetic procedure trends [Internet]. Arlington Heights, IL: ASPS; c2017 [cited 2019 Mar 7]. Available from: https://www.plasticsurgery.org/documents/ News/Statistics/2016/cosmetic-procedure-trends-2016.pdf.

15. Aly A, Avila E, Cram AE. Endoscopic plastic surgery. Surg Clin North Am 2000;80:1373-82.

16. Klingensmith ME, Awad M, Delman KA, et al. Early results from the flexibility in surgical training research consortium: resident and program director attitudes toward flexible rotations in senior residency. J Surg Educ 2015;72:e151-7.

17. Rosen JM, Long SA, McGrath DM, et al. Simulation in plastic surgery training and education: the path forward. Plast Reconstr Surg 2009; 123:729-38.

18. Jang HW, Kim KJ. Use of online clinical videos for clinical skills training for medical students: benefits and challenges. BMC Med Educ 2014; 14:56.

19. Fearing N, Bachman S, Holzman M, et al. Evaluation of a video-based curriculum for laparoscopic biliary surgery: a pilot study from the SAGES MIS Web Learning Center. Surg Endosc 2010;24:3141-3.

20. Wojcik BM, Fong ZV, Patel MS, et al. Structured operative autonomy: an institutional approach to enhancing surgical resident education without impacting patient outcomes. J Am Coll Surg 2017;225:713-24.

21. Teman NR, Gauger PG, Mullan PB, et al. Entrustment of general surgery residents in the operating room: factors contributing to provision of resident autonomy. J Am Coll Surg 2014;219:778-87.

22. American Society of Plastic Surgeons (ASPS). 2017 Cosmetic plastic surgery statistics cosmetic procedure trends [Internet]. Arlington Heights, IL: ASPS; c2018 [cited 2019 Mar 7]. Available from: https://www.plasticsurgery.org/ documents/News/Statistics/2017/plastic-surgery-statisticsfull-report-2017.pdf.

23. Richards MK, McAteer JP, Drake FT, et al. A national review of the frequency of minimally invasive surgery among general surgery residents: assessment of ACGME case logs during 2 decades of general surgery resident training. JAMA Surg 2015;150:169-72.

24. Schauer PR, Page CP, Stewart RM, et al. The effect of laparoscopic cholecystectomy on resident training. Am J Surg 1994;168:566-9.

25. Heine SJ, Lehman DR, Peng K, et al. What's wrong with cross-cultural comparisons of subjective Likert scales?: The reference-group effect. J Pers Soc Psychol 2002;82:903-18. 